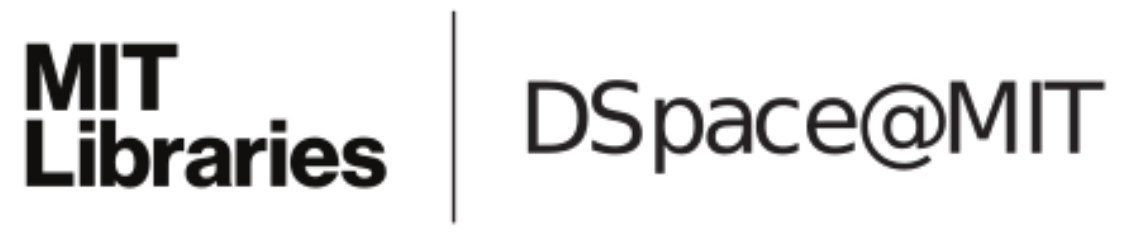

\author{
MIT Open Access Articles
}

\section{Potential of Negative Valve Overlap for Part Load Efficiency Improvement in Gasoline Engines}

The MIT Faculty has made this article openly available. Please share how this access benefits you. Your story matters.

Citation: Rodriguez, J. Felipe, and Wai Cheng. "Potential of Negative Valve Overlap for Part Load Efficiency Improvement in Gasoline Engines." WCX: SAE World Congress Experience, 10-12 April, 2018, Detroit, Michigan, SAE International, 2018.

As Published: https://doi.org/10.4271/2018-01-0377

Publisher: SAE International

Persistent URL: http://hdl.handle.net/1721.1/116165

Version: Author's final manuscript: final author's manuscript post peer review, without publisher's formatting or copy editing

Terms of use: Creative Commons Attribution-Noncommercial-Share Alike 


\title{
Potential of Negative Valve Overlap for Part Load Efficiency Improvement in Gasoline Engines
}

\author{
Author, co-author (Do NOT enter this information. It will be pulled from participant tab in \\ MyTechZone) \\ Affiliation (Do NOT enter this information. It will be pulled from participant tab in MyTechZone)
}

\begin{abstract}
This paper reports on the potential of negative valve overlap for improving the net indicated thermal efficiency of gasoline engines during part load. Three fixed fuel flow rates, resulting in indicated mean effective pressures of up to 6 bar, were investigated. At low load, negative valve overlap (NVO) significantly reduces the pumping loses during the gas exchange loop, achieving up to $7 \%$ improvement in indicated efficiency compared to the baseline. Similar efficiency improvements are achieved by positive valve overlap (PVO), with the disadvantage of worse combustion stability from a higher residual gas fraction. As the load increases, achieving the wide-open throttle limit, the benefits of NVO for reducing the pumping losses diminish, while the blow-down losses from early exhaust valve opening increase. However, a symmetric NVO strategy combined with a shorter exhaust duration has a higher potential for reduction in part-load fuel consumption, as the exhaust valve opening timing can be optimized to minimize the blow-down losses.
\end{abstract}

\section{Introduction}

Improving the thermodynamic efficiency of spark ignition (SI) engines operating in part load one of the key levers for improving the in-use fuel consumption of passenger vehicles. The locus of engine operating points over different driving cycles depends on the full load engine curve, and the aerodynamic, rolling resistance, gravitational and inertial forces resulting from vehicle operation over the driving cycle. As an example, Figure 1 shows the locus of engine operating points resulting from the vehicle simulation of a typical 2.5 liter, naturally aspirated (NA) mid-size sedan over the Urban Dynamometer Driving Schedule (UDDS). Over the UDDS, this representative US mid-size sedan mostly operates in the low engine load region, where the brake thermal efficiency is below $30 \%$. The average operating point of this representative example has an approximate brake mean effective pressure (BMEP) of 3.3 bar.

The departure from the ideal thermodynamic efficiency of (SI) engines is due to several factors: limited flame speed, deviations from the ideal isentropic compression and expansion processes, blow-down losses at exhaust valve opening (EVO), and pumping losses associated with intake throttling in stoichiometric engines. Figure 2 shows a pressurevolume diagram of a SI engine during part load.

Page 1 of 10

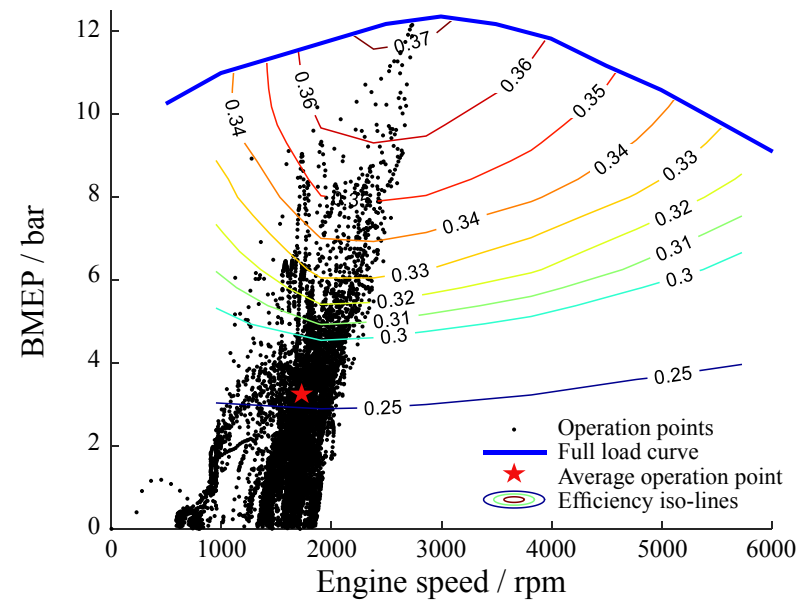

Figure 1. Operating points on the engine map (Mid-size sedan vehicle, 2.5L NA engine with compression ratio of 11.5:1) determined using Autonomie over the UDDS cycle. Spark timings at MBT timing. Adapted from: Jo, 2016 [1]

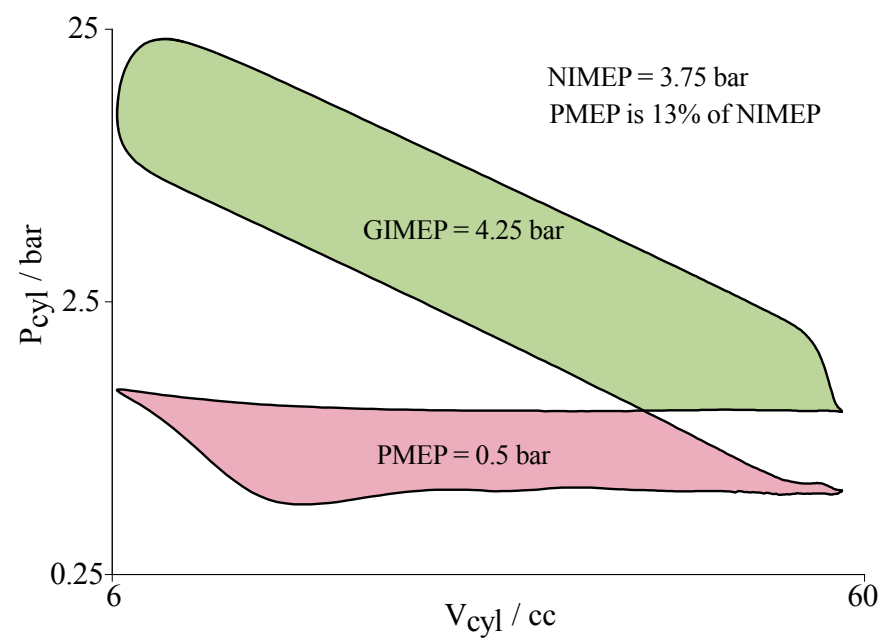

Figure 2. Pressure - volume diagram for a part load operation in a SI engines (logarithmic scales) at 3.75 bar NIMEP

At low load, the efficiency losses are dominated by the pump mean effective pressure (PMEP); the latter represents a significant share of the net indicated mean effective pressure (NIMEP). In the operating point shown in Figure 2, which is one of the baseline operating points 
for this study, the PMEP accounts for $13 \%$ of NIMEP. Reducing the pumping losses has been one of the key areas of research in engine development over the past decades. Valve timing strategies, and the flexibility provided by variable valve actuation (VVA) systems have proven effective for reducing part load pumping losses. Early intake valve closing (IVC) and late IVC are the two most common approaches for PMEP reduction. In this paper, we explore the potential of another valve timing strategy, namely negative valve overlap (NVO). NVO strategies consist of a combination of early exhaust valve closing (EVC) and late intake valve opening (IVO), resulting in crank angle $\left({ }^{\circ} \mathrm{CA}\right)$ periods close to top dead center (TDC), where intake and exhaust valves are simultaneously closed.

Negative valve overlap (NVO) has been widely studied in gasoline compression ignition, low temperature combustion (e.g., HCCI, CAI, SACI) for controlling combustion phasing. Several studies [2]-[7] have investigated the thermal and chemical effects of NVO on the auto-ignition behavior of the fuel mixture. The trapping and recompression of internal residual gases provide an additional degree of freedom for controlling the thermo-chemistry of combustion. The recompression of residual gas during $\mathrm{NVO}$ enables a better control of the charge temperature, and of the charge reactivity through reacting and reforming, if fuel injection takes place during $\mathrm{NVO}[2,3,7]$.

Studies on the impact of NVO on conventional spark combustion are however more limited. Pischinger et al. [8] conceptually analyzed the benefits of NVO on internal exhaust gas recirculation (EGR) control, charge temperature, fuel mixture preparation and flow conditions at intake valve opening. However, no testing or simulation results were provided.

Bonatesta and Shayler [9] investigated the flame development angle and the rapid burn angle for different valve timings. At slight negative valve overlap $\left(0-20^{\circ} \mathrm{CA} \mathrm{NVO}\right)$, neither the flame development nor the rapid burn angle showed a strong dependence on the NVO setting in this range, possibly due to the small change in residual gas fraction compared to no valve overlap.
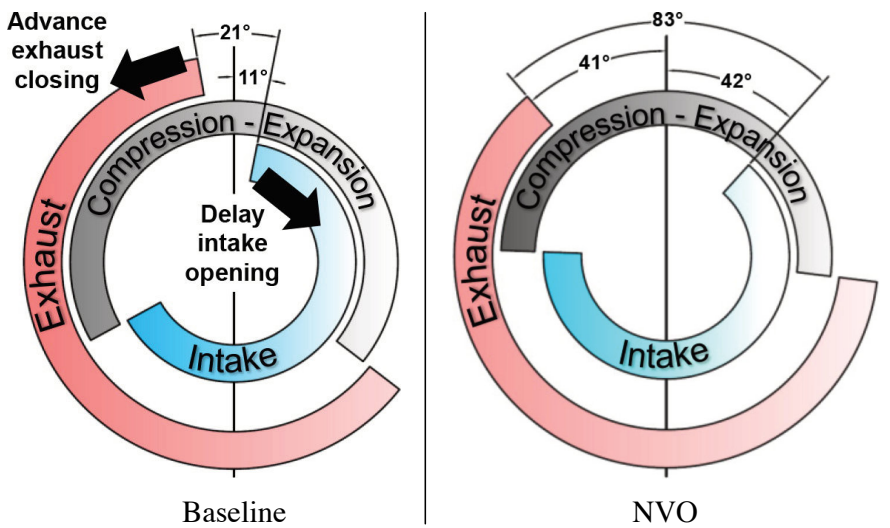

Figure 3. Valve timing diagram for the engine used. The intake and exhaust valve openings have a duration of $220^{\circ} \mathrm{CA}$. The position shown on the left is the stock valve timing with de-energized VVT solenoids. The black arrows represent the direction of phasing for NVO. The position shown on the right is the most aggressive NVO pursued, with de-energized VVT solenoids.

More recently, Chang et al. [10] investigated the potential of negative valve overlap for charge dilution with internal EGR, combined with direct fuel injection during the NVO event to extend the dilution limit of combustion in gasoline engines, through partial fuel reforming. The researchers found a $22 \%$ improvement in BSFC with the use of $32 \%$ EGR, $80^{\circ} \mathrm{CA} \mathrm{NVO}$, and TDC injection, compared to the reference Page 2 of 10 operating point without EGR, and stock valve and injection timings. The researchers also measured a $\mathrm{CO}$ and NOx emissions advantage, although no results were presented for PM/PN emissions, which could be problematic with TDC injection due to piston crown impingement.

In this paper, we analyze the potential of NVO in improving the part load efficiency of SI engines at three different engine loads. We analyze the effects of NVO on different volume specific work metrics, as well as on combustion stability. The experimental work has been complemented by engine cycle simulation to quantify the effect of NVO on parameters that were not possible to measure.

This study was carried out at the Sloan Automotive Laboratory of the Massachusetts Institute of Technology, under the financial and technical sponsorship of the Consortium on Engine and Fuels Research at MIT. It is an extension of previously published work on the influence of valve timing and NVO strategies on the pollutant emissions during cold-start carried out by the authors [11], [12].

\section{Methodology}

\section{Engine set-up}

The engine used in this study was a commercial turbocharged SI direct injection engine. The 4-cylinder, 2-liter engine featured centrally mounted spark plugs and side-mounted electromagnetic injectors. The injectors have a $52^{\circ}$ cone angle, a $25^{\circ}$ inclination from the horizontal and 6 holes.

The variable valve timing (VVT) system was hydraulically actuated, and had an authority of $50^{\circ} \mathrm{CA}$ on each camshaft and allows the advancing of the intake valve timing and the retarding of the exhaust valve timing. The parked valve timing and direction of actuation of the VVT system is shown in Figure 3. For the investigations of delayed intake timing and advanced exhaust timing, the parked position of the camshafts had to be mechanically modified. The new parked positions of the camshafts were achieved by rotating the camshafts 2 teeth of the cam sprockets. Since the cam sprockets had 46 teeth, a rotation of 2 teeth corresponds to a change in camshaft timing of $15.6^{\circ}$ of camshaft rotation, or approximately $31{ }^{\circ} \mathrm{CA}$.

Further information on the engine geometry, including the baseline valve timing can be found in Table 1 .

Table 1. Specifications of the base engine, stock parked valve timing

\begin{tabular}{|l|l|}
\hline Displacement & $1998 \mathrm{cc}$ \\
\hline Bore / Stroke & $86 / 86 \mathrm{~mm}$ \\
\hline Connecting Rod & $145.5 \mathrm{~mm}$ \\
\hline Compression ratio & $9.2: 1$ \\
\hline Fuel pressure & $50 \mathrm{bar}$ \\
\hline Intake Valve Open / Close & $10^{\circ} / 240^{\circ}$ aTDC-i @ $0.2 \mathrm{~mm} \mathrm{lift}$ \\
\hline Max. intake valve lift & $10.3 \mathrm{~mm} @ 126^{\circ} \mathrm{aTDC}-\mathrm{i}$ \\
\hline Exhaust Valve Open / Close & $-232^{\circ} /-10^{\circ}$ aTDC-i @ $0.2 \mathrm{~mm} \mathrm{lift}$ \\
\hline Max. exhaust valve lift & $10.3 \mathrm{~mm} @-125^{\circ}$ aTDC-i \\
\hline
\end{tabular}

The experiments were carried out at constant injection timing. To minimize the impact of fuel pressure and temperature on the fuel delivery, the fuel was cooled down by a chiller to $20^{\circ} \mathrm{C}$ and was 
pressurized to 50 bar by a hydro-pneumatic accumulator using high pressure nitrogen. This allowed the fuel pressure to be set independently from engine operation, and minimized pressure fluctuations. The fuel used was a Tier II EEE certification gasoline with a carbon mass fraction of $86.5 \%$ and a stoichiometric air to fuel ratio of 14.578 . The fuel density was $0.743 \mathrm{~kg} / 1$ and had a lower heating value of $43 \mathrm{MJ} / \mathrm{kg}$. The ambient air was not conditioned and had a temperature between 25 and $29^{\circ} \mathrm{C}$. The intake air was cooled down by an intercooler and subsequently heated obtain an approximate temperature of $23^{\circ} \mathrm{C}$ at the intake. The engine coolant temperature was kept at $85^{\circ} \mathrm{C}$.

The in-cylinder pressure was measured with a high-temperature piezoelectric pressure transducer, Kistler $6125 \mathrm{~A}$, mounted in the cylinder head between the intake and exhaust valves and approximately $2 \mathrm{~cm}$ from the cylinder wall. The charge output of the pressure sensors was amplified and converted to an analog signal using a charge amplifier, Kistler 5010b. The pressure signal from the charge amplifier exhibits a long-term drift at an approximate rate of $0.03 \mathrm{pC} / \mathrm{s}$ [13]. At steady-state operation the cylinder pressure was corrected by pegging the cylinder pressure output to a known absolute pressure level. The intake manifold absolute pressure sensor was used for this end. The pegging of the signals was done at the beginning of the compression stroke, where, due to the low piston and flow speeds, the intake manifold and the cylinder contents are in mechanical equilibrium [14]. Figure 4 shows a diagram of the experimental setup.
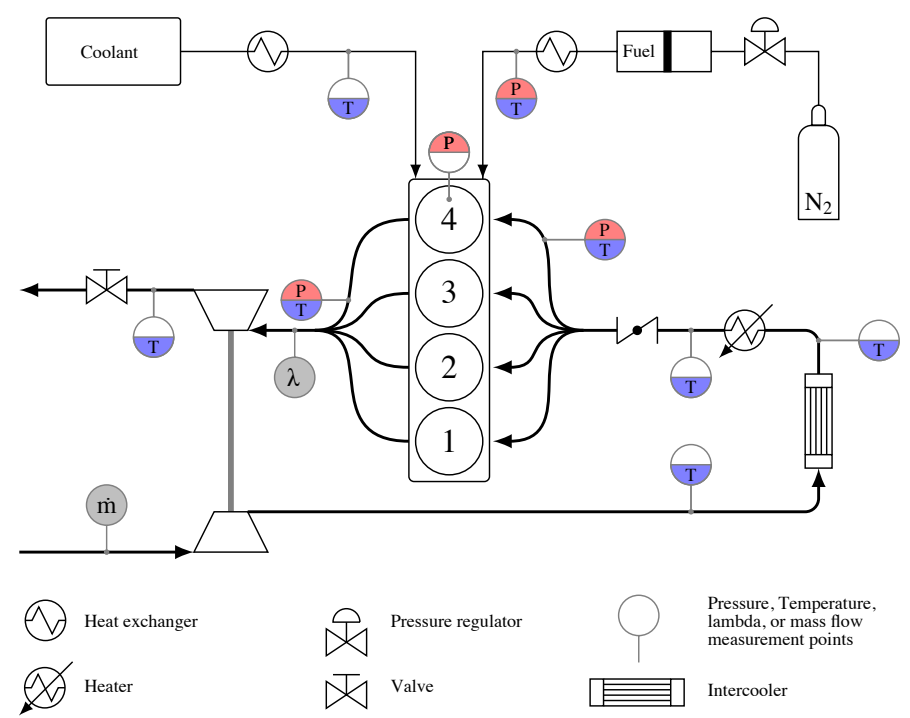

Pressure, Temperature, lambda, or mass flow

Intercooler

Figure 4. Diagram of the experimental setup and measurement points

\section{Experiments description}

In this study, a total of 84 different engine operating points were investigated. These correspond to 3 different fuel flow rates, and 28 different valve timings. The valve timings studied are shown in Figure 5. A valve timing step of $16^{\circ} \mathrm{CA}$ was used to cover the valve timing map. The valve timing ranges used in this study were limited by the authority of the valve phasing system. The hydraulically actuated VVT system, with an authority of $50^{\circ} \mathrm{CA}$ for both the intake and exhaust camshaft, advanced the intake valve timing and retarded the exhaust valve timing.

Page 3 of 10
To cover both the positive and negative valve overlap ranges, two different parked valve timing settings (i.e., no VVT actuation) were used. These are represented by the black stars in Figure 5. The first parked valve timing, corresponding to an IVO of $10^{\circ} \mathrm{CA}$ aTDC-i and an EVC of $-10^{\circ} \mathrm{CA}$ aTDC-i, allowed for the study of the positive valve overlap (PVO) range (see Figure 6). This valve timing setting is also the stock parked valve timing position of the engine, and was used as the baseline valve timing for the comparisons shown in the next section. The second parked valve timing used, corresponding to an IVO of $42^{\circ} \mathrm{CA}$ aTDC-i and an EVC of $-42^{\circ} \mathrm{CA}$ aTDC-i, was selected to study the NVO range (see Figure 6).

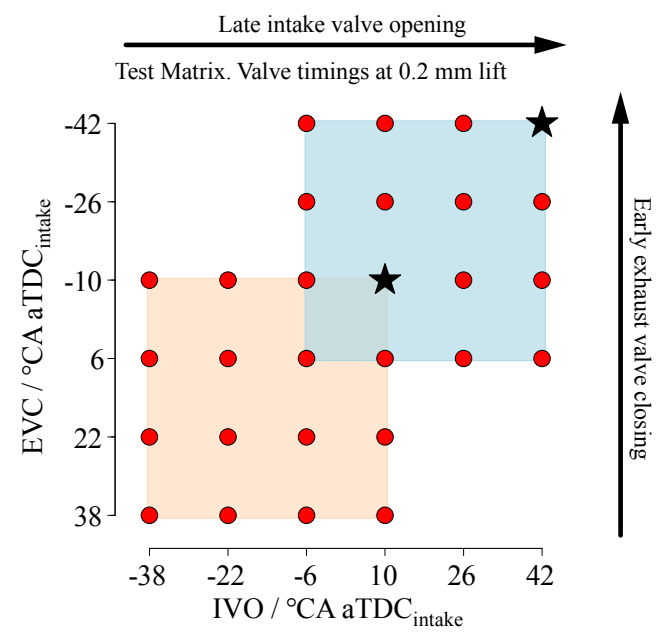

Figure 5. Valve timing experiment matrix. The two black stars represent the parked valve timing settings (i.e., no VVT actuation) used to cover the valve timing map. The orange and blue squares represent the range covered by the VVT system from the corresponding parked valve timings.

Figure 6 shows the valve overlap map as a function of valve timing. Of the valve timings studied, 13 settings fall in the PVO range, 2 are close to the no-valve-overlap line, and 13 are on the NVO range. The valve timing settings highlighted in green in Figure 6 will be discussed in detail in the next section (see Table 3 ).

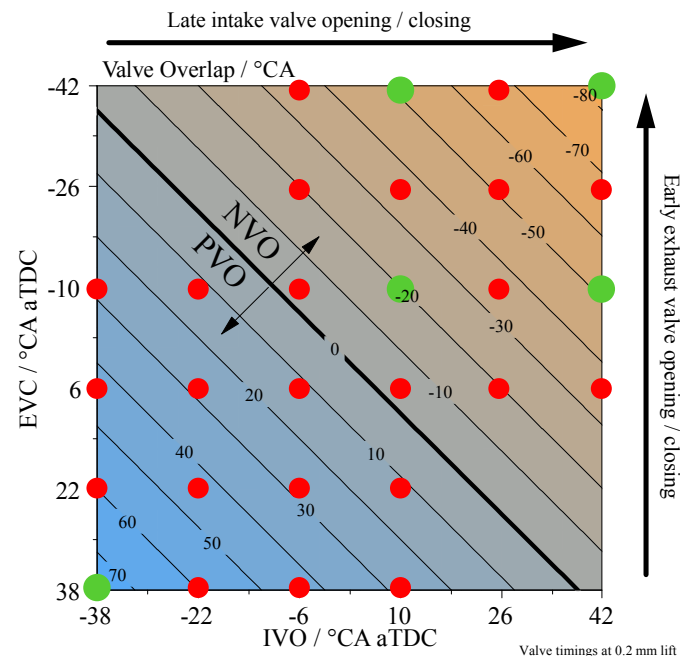

Figure 6. Positive and negative valve overlap regions as a function of valve timing. The bigger green points highlight the individual valve timings that will be discussed in detail.

The valve timing settings shown in Figure 5 and Figure 6 were studied at three different fueling conditions, resulting in three 
different engine loads. The steady-state experiments were carried out at constant fuel injection duration. In each case, the throttle was adjusted to maintain stoichiometric air/fuel ratio. The choice of using fixed amount of fuel is because that is the quantity which could be readily held constant, while the NIMEP could change substantially with change of valve timing. Three injection durations were studied: $1300 \mu \mathrm{s}, 1500 \mu \mathrm{s}$, and $1800 \mu \mathrm{s}$. The corresponding fuel masses injected per cycle are shown in Table 2 . In all cases the start of injection (SOI) was set at $105^{\circ} \mathrm{CA}$ aTDC-i (i.e., during intake valve opening), as this SOI resulted in the best combustion stability across the different operating conditions. For each steady state run (i.e., each valve time, fuel mass combination), the ignition timing was swept to find the maximum brake torque (MBT). The resulting center of combustion, CA50, was between 7 and $9^{\circ} \mathrm{CA}$ aTDC-c. For each steady-state experiment, 156 cycles were recorded and the average results are presented and discussed in the next section.

Table 2. Engine operating points investigated

\begin{tabular}{|l|l|l|l|}
\hline Load point & $\mathbf{1}$ & $\mathbf{2}$ & $\mathbf{3}$ \\
\hline Engine speed & $1200 \mathrm{rpm}$ & $1200 \mathrm{rpm}$ & $1200 \mathrm{rpm}$ \\
\hline Fuel mass per cyl. & $14.7 \mathrm{mg}$ & $16.9 \mathrm{mg}$ & $20.1 \mathrm{mg}$ \\
\hline Pulse duration & $1300 \mu \mathrm{s}$ & $1500 \mu \mathrm{s}$ & $1800 \mu \mathrm{s}$ \\
\hline Injection timing & $105^{\circ} \mathrm{CA}$ aTDC & $105^{\circ} \mathrm{CA}$ aTDC & $105^{\circ} \mathrm{CA}$ aTDC \\
\hline Spark timing & $\mathrm{MBT}$ & $\mathrm{MBT}$ & $\mathrm{MBT}$ \\
\hline NIMEP & $\sim 4 \mathrm{bar}$ & $\sim 5 \mathrm{bar}$ & $\sim 6 \mathrm{bar}$ \\
\hline
\end{tabular}

\section{Results and discussion}

This section presents the results of the investigations at the valve timings defined in Figure 5 for the three fueling conditions shown in Table 2. Qualitatively, the experimental results show similarities amongst the three different fueling conditions studied. Nevertheless, as the engine load increases and the pumping losses decrease, the effectiveness of NVO valve timing strategies to improve the part-load thermal efficiency of the engine is reduced. In general, the results show a lower sensitivity to changes in valve timing in the NVO range as the engine load increases. Figure 7 summarizes the greatest observed changes in net indicated efficiency as a function of valve overlap, with respect to the baseline valve timing defined in Table 1.

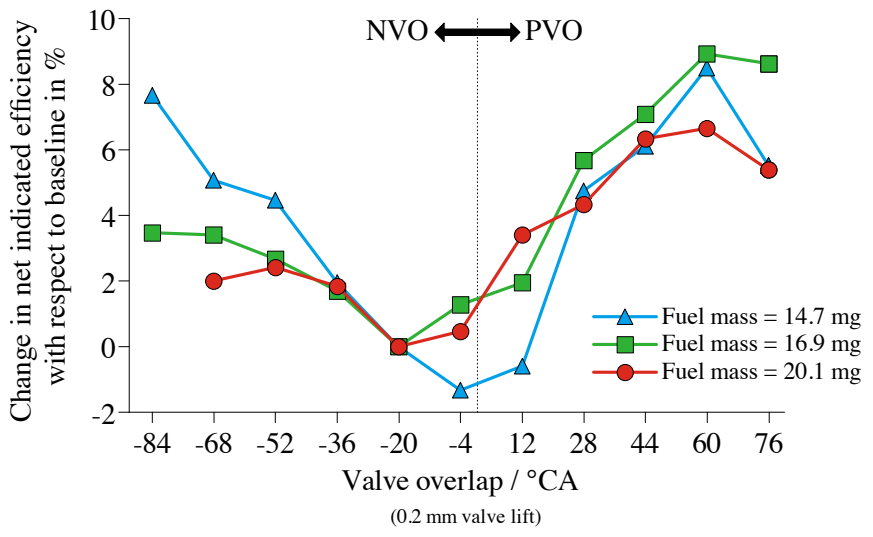

Figure 7. Change in net indicated thermal efficiency as a function of valve overlap. Different valve timing settings can result in the same valve overlap. The results shown correspond to the greatest positive change in efficiency observed for a given valve overlap.

Page 4 of 10
As shown in Figure 7, the lowest engine load, with an injected mass of $14.7 \mathrm{mg}$ per cylinder per cycle, shows the greatest sensitivity to changes in valve overlap. Most notably, for the lowest engine load, the benefits of NVO and PVO are comparable. The NVO strategy, however, does not deteriorate the combustion stability. For the other two engine loads studies, with a fuel mass of 16.9 and $20.1 \mathrm{mg}$ per cylinder per cycle, respectively, exhibit only modest efficiency benefits for valve timings in the NVO range, while those in the PVO range maintain their effectiveness.

Due to the higher sensitivity of the low load point to valve timing settings in the NVO range, the load point 1 (i.e., $14.7 \mathrm{mg} /$ cyl./cycle) will be analyzed in detail, to explain the trends observed in Figure 7. The 4 specific valve timings used to understand the aforementioned trends are shown in Table 3 . The discussion for these valve timings is found in the accompanying paragraphs to Figures 11 through 19. The differences to the other two part-load operating points are addressed thereafter. Closing this section, we include a short discussion providing a possible pathway to address the pitfalls of NVO valve timings.

\section{Experimental results, $14.7 \mathrm{mg}$ of fuel per cylinder}

Figure 8 shows the contour diagram for the net indicated thermal efficiency of the engine ( $\eta$ NIMEP) as a function of the IVO and EVC. The contour plots are based on the 28 experimental measurements defined in Figure 5, and are interpolated using a thin plate spline. As indicated in Figure 6, the NVO range is in the upper right quadrant, while the PVO range is in the lower left quadrant. The indicated efficiency at the baseline valve timing (see Table 1) is $29.7 \%$. The improvement in the NVO and PVO range is similar, with peak $\eta$ NIMEP of $31.9 \%$ in the NVO range, and $32.2 \%$ in the PVO range.

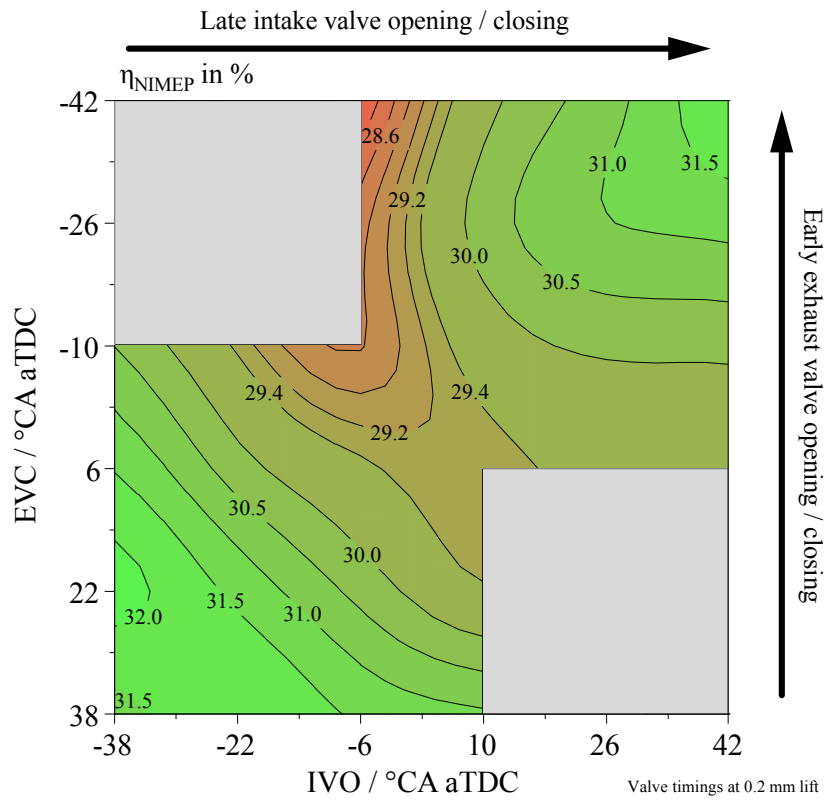

Figure 8. Net indicated thermal efficiency as a function of valve timing for a constant fuel injection of $14.7 \mathrm{mg}$ per cylinder per cycle

To illustrate better the impact of valve timing on $\eta_{\text {NIMEP }}$, Figure 9 depicts the relative change in indicated efficiency with respect to the baseline valve timing. The corresponding changes in $\eta$ NIMEP in the

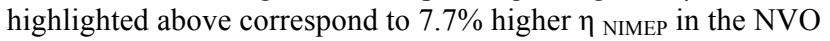
range, and $8.5 \%$ in the $\mathrm{PVO}$ range. In the PVO range, the iso- 
efficiency lines in Figure 9 are roughly parallel to the iso-PVO lines in Figure 6; that is, the efficiency improvements in the PVO range are mainly a function of the valve overlap angle, and are approximately independent from the selection of IVO and EVC. In the NVO range however, the iso-efficiency lines are curved in such a way that the efficiency change in the NVO range is not only a function of the $\mathrm{NVO}$, but also of the IVO and EVC selection. For a given NVO, the highest efficiency is achieved at the tangency point between the isoefficiency and the iso-NVO lines. This tangency points show that the highest benefit is achieved for a symmetric NVO, that is, where ${ }^{\circ} \mathrm{CA}$ distance to TDC is the same for the EVC and IVO events.

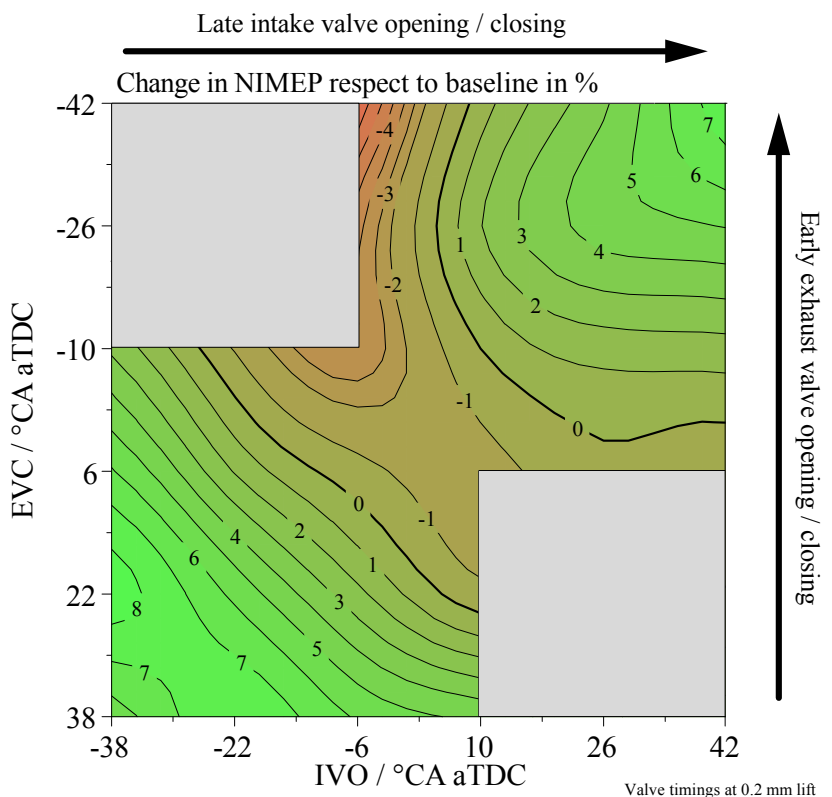

Figure 9. Relative change in net indicated thermal efficiency with respect to the baseline valve (fuel mass $=14.7 \mathrm{mg} /$ cyl./cycle)

Despite the similar net indicated efficiency benefits in the PVO and NVO ranges, the combustion stability deteriorates rapidly as the PVO increases. Figure 10 shows the contour plots for the two combustion stability metrics studied, the coefficient of variation $(\mathrm{CoV})$ and the lowest normalized value (LNV) of NIMEP. The statistical examination of the cycle-by-cycle combustion variability is based on the 156 cycles that were recorded for each operating point. The highest combustion stability, that is, the lowest $\mathrm{CoV}$ and highest $\mathrm{LNV}$, is achieved at no valve overlap. In the NVO range, both metrics deteriorate slightly with increasing NVO, driven by higher residual gas fractions. At the most aggressive, symmetric NVO, the CoV has a value of $1.9 \%$ and the LNV of $92 \%$. In the PVO range, the combustion cycle-to-cycle variability increases rapidly with valve overlap, as the internal exhaust gas recirculation increases. As shown in Figure 10, the iso-lines for $\mathrm{CoV}$ and $\mathrm{LNV}$ in the PVO range are approximately parallel to the iso-PVO lines shown in Figure 6. Therefore, the combustion stability is highly dependent on the degree of PVO, while the selection of IVO and EVC for a given PVO plays a secondary role. At the most aggressive PVO setting, the CoV increases to $19.4 \%$, while the LNV decreases to $-9.6 \%$ indicating the presence of misfiring cycle.

To analyze the mechanisms behind the observed trends in thermal efficiency and combustion stability for the different valve timings, the pressure traces of the five particular valve timings shown in Table 3 are discussed in detail. These five cases are: Baseline, late IVO, early EVC, symmetric NVO, and symmetric PVO.

Page 5 of 10
Table 3. Valve timings for which the pressure traces are analyzed in detail

\begin{tabular}{|c|l|l|}
\hline Case name & \multicolumn{1}{|c|}{ Intake timing } & Exhaust timing \\
\hline Baseline & IVO $=10^{\circ} \mathrm{CA}$ aTDC- $\mathrm{i}$ & $\mathrm{EVC}=-10^{\circ} \mathrm{CA}$ aTDC-i \\
\hline Late IVO & $\mathrm{IVO}=42^{\circ} \mathrm{CA}$ aTDC- $\mathrm{i}$ & $\mathrm{EVC}=-10^{\circ} \mathrm{CA}$ aTDC-i \\
\hline Early EVC & $\mathrm{IVO}=10^{\circ} \mathrm{CA}$ aTDC-i & $\mathrm{EVC}=-42^{\circ} \mathrm{CA}$ aTDC-i \\
\hline Symmetric NVO & $\mathrm{IVO}=42^{\circ} \mathrm{CA}$ aTDC-i & $\mathrm{EVC}=-42^{\circ} \mathrm{CA}$ aTDC-i \\
\hline Symmetric PVO & $\mathrm{IVO}=-38^{\circ} \mathrm{CA}$ aTDC-i & $\mathrm{EVC}=38^{\circ} \mathrm{CA}$ aTDC-i \\
\hline
\end{tabular}
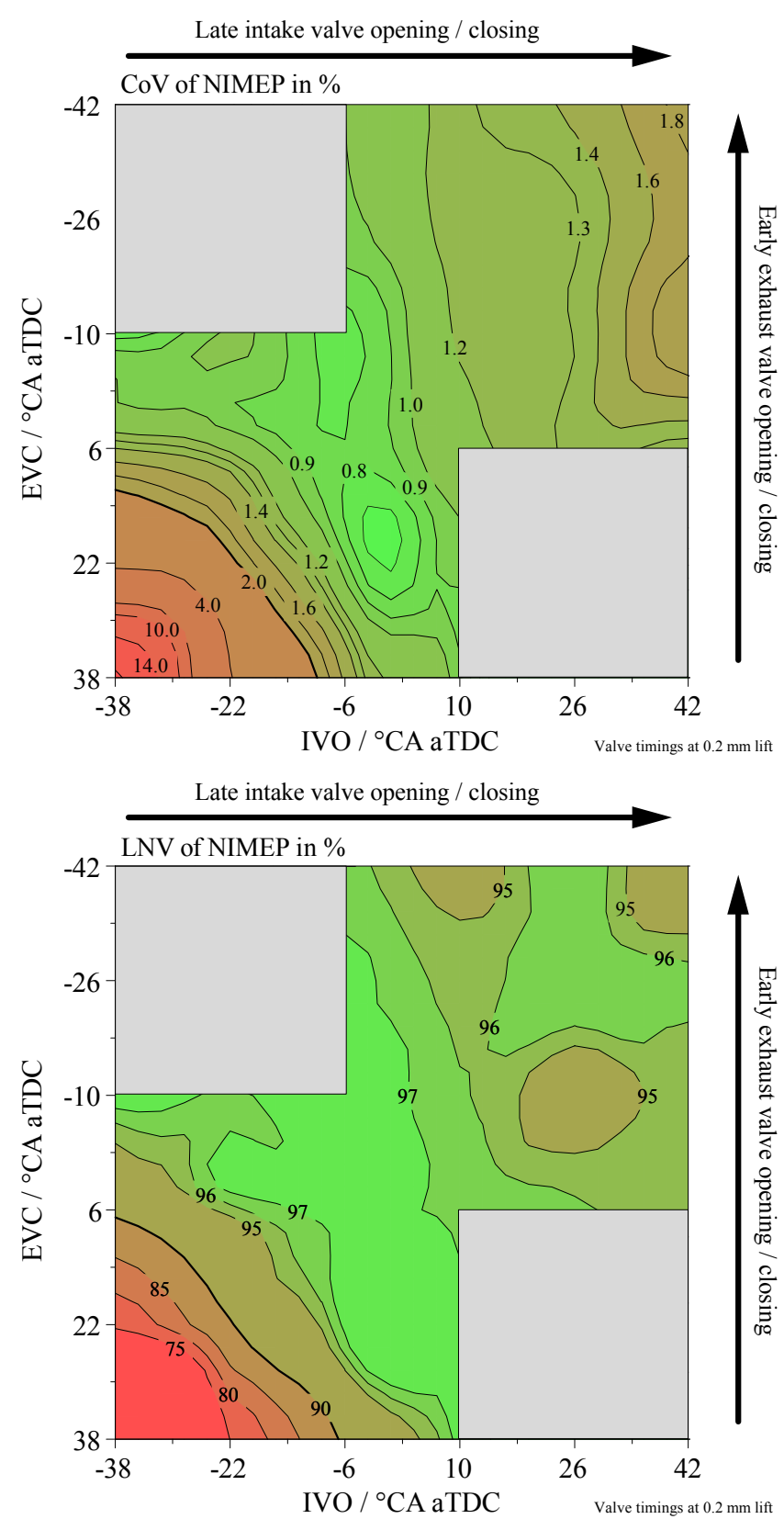

Figure 10. Combustion stability, CoV (top) and LNV (bottom), as a function of valve timing for a constant fuel injection of $14.7 \mathrm{mg}$ per cylinder per cycle

Figure 11 illustrates the main mechanism by which the well-known PVO valve timing strategy increases the indicated efficiency at partload in gasoline engines. As shown in Figure 11, the simultaneous 
opening of the intake and exhaust valves during the gas exchange process decreases the pumping losses in $50 \%$ with respect to the baseline valve timing. The pressure differential between the exhaust and intake manifolds results in a flow of the burned gases from the exhaust port, into the cylinder, and ultimately into the intake port.

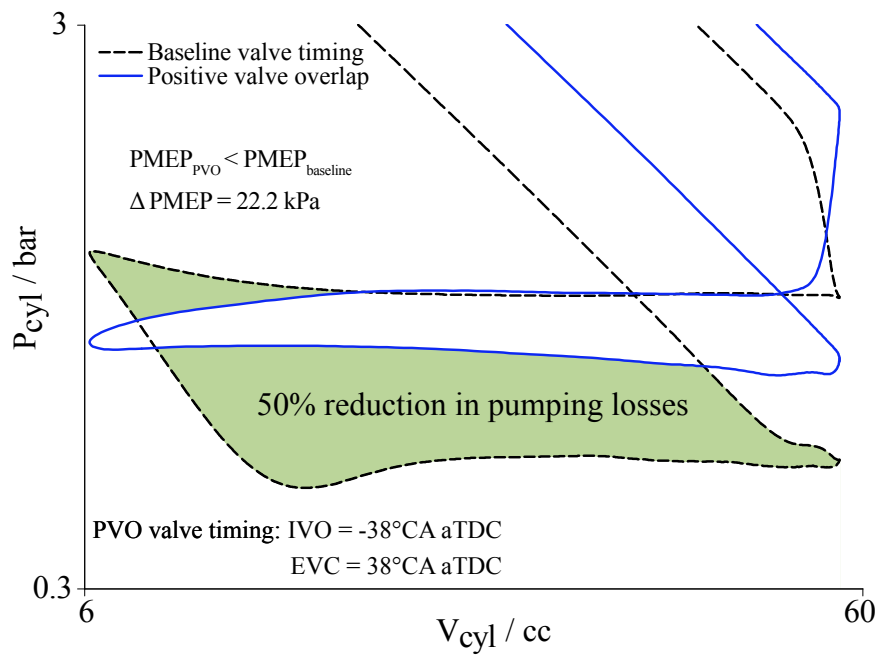

Figure 11. Comparison of the pumping loops (logarithmic scales) of the baseline and Symmetric PVO valve timings (fuel mass $=14.7 \mathrm{mg} / \mathrm{cyl} . / \mathrm{cycle}$ )

Effectively, the PVO strategy increases residual gas fraction $\left(\mathrm{x}_{\mathrm{r}}\right)$, which must be compensated by a wider throttle opening to maintain the oxygen content required for stoichiometric combustion. Figure 12 shows $\mathrm{x}_{\mathrm{r}}$ as a function of valve timing. In the PVO range, $\mathrm{x}_{\mathrm{r}}$ increases linearly with valve overlap at a rate of $\sim 0.4 \% /{ }^{\circ} \mathrm{CA}_{\mathrm{PVO}}$. The rapid increase in $\mathrm{x}_{\mathrm{r}}$ and the associated deterioration in combustion stability, limits the applicability of PVO in low loads as discussed above.

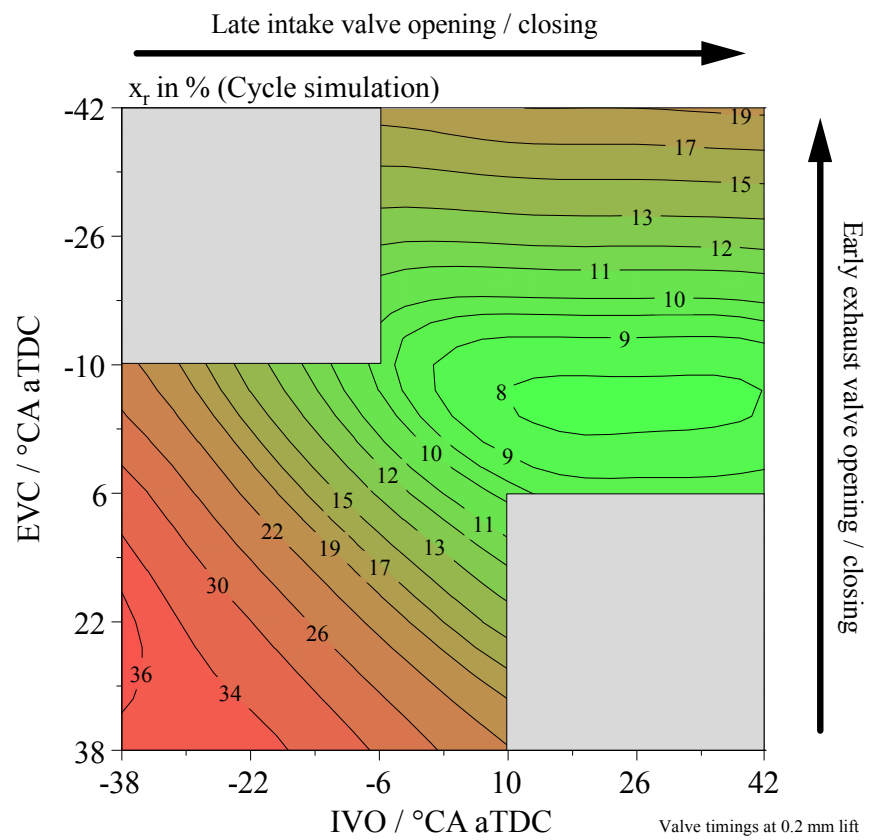

Figure 12. Residual gas fraction as a function of valve timing for a constant fuel injection of $14.7 \mathrm{mg}$ per cylinder per cycle

Nonetheless, charge dilution by residual gases is not the only way to increase the net indicated thermal efficiency at part load. The Late
IVO strategy results in the same residual gas fraction with respect to the baseline (see Figure 12) and increases the $\eta_{\text {NIMEP }}$ by $2 \%$ (see Figure 9). The source of the efficiency gains can be observed in Figure 13 and Figure 14. The Late IVO strategy reduces the pumping losses by lowering the effective intake stroke. During the initial part of the compression stroke, the late intake valve closing allows the fresh cylinder contents to be pushed back into the intake manifold, reducing the effective compression stroke. The lower effective intake stroke must be compensated by a wider throttle setting, reducing the pumping losses.

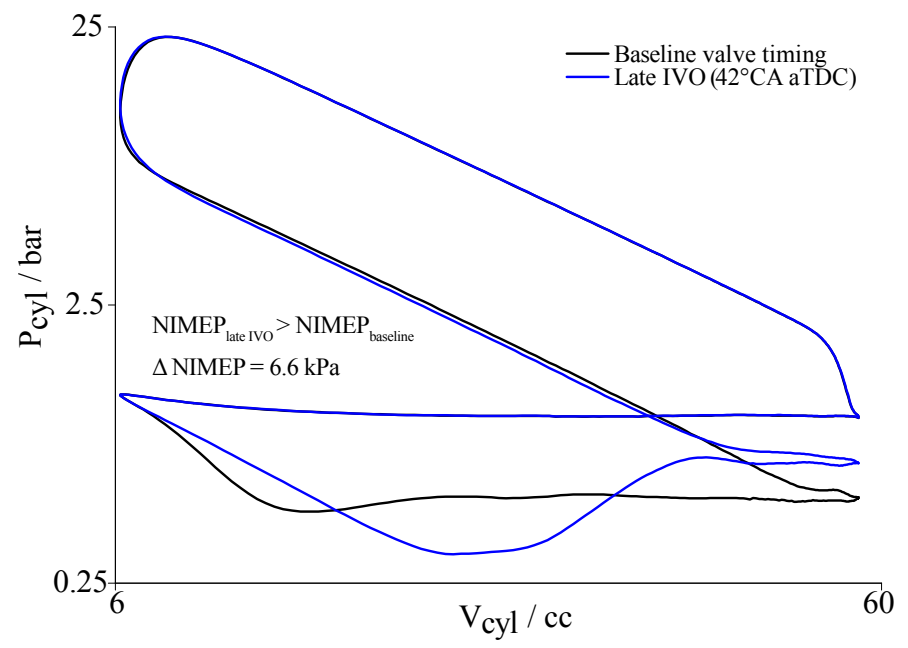

Figure 13. $\log (\mathrm{P})-\log (\mathrm{V})$ diagrams for baseline and Late IVO valve timings for a constant fuel injection of $14.7 \mathrm{mg}$ per cylinder per cycle

As can be seen in Figure 13, the high pressure loop are identical between the baseline and Late IVO cases, with the exception of the early part of the compression stroke. In contrast, the pumping loops are different. The Late IVO setting results in a rapid decrease in cylinder pressure during the early intake stroke. This additional pumping loss is arrested when the intake valve opens. However, the low initial cylinder pressure has potential benefits for the mixture formation and the pollutant emissions, particularly during cold start [11].

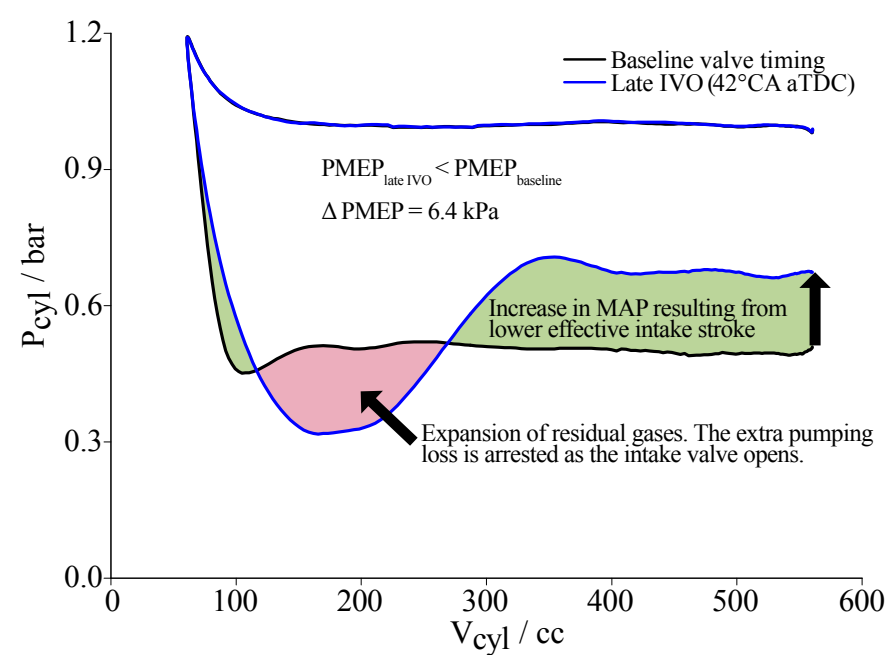

Figure 14. Comparison of the pumping loops (linear scales) of the baseline and Late IVO valve timings (fuel mass $=14.7 \mathrm{mg} / \mathrm{cyl} . /$ cycle)

Page 6 of 10 
Figure 15 shows the pressure-volume diagrams for the baseline and the Early EVC valve settings. The pressure trace of the Early EVC setting is differs significantly from the baseline. There is a significant rise in exhaust pressure due to charge recompression via early EVC. The charge is also less expanded in the expansion stroke. The engine, however, needs to be de-throttled to maintain $\lambda=1$ for the same fuel injected. The different competing effects balance out and there is no efficiency gain or deterioration compared to the baseline.

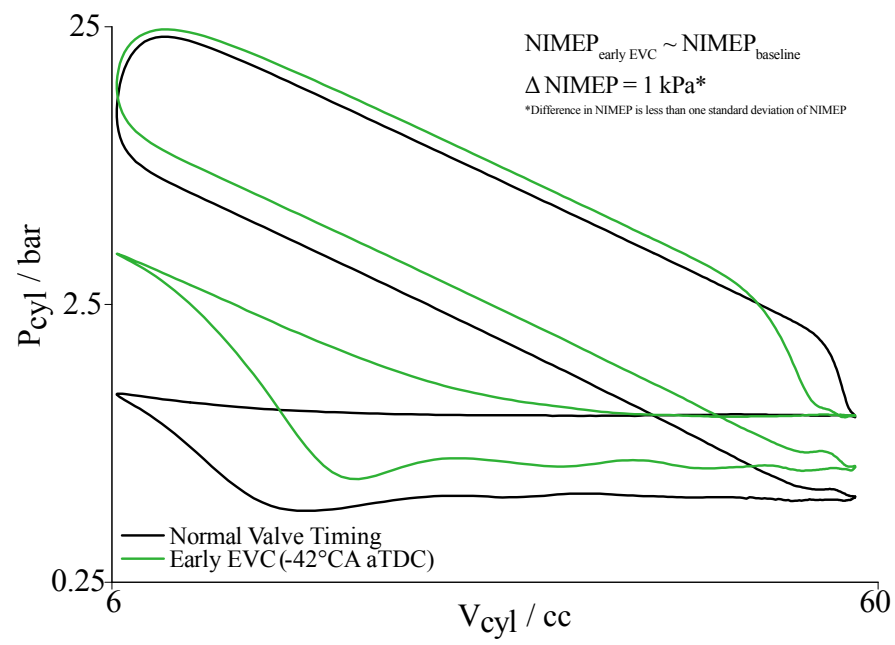

Figure 15. $\log (\mathrm{P})-\log (\mathrm{V})$ diagrams for baseline and Early EVC valve timings for a constant fuel injection of $14.7 \mathrm{mg}$ per cylinder per cycle

In the NVO range, the residual gas fraction is a function of the EVC timing and is fairly independent from the NVO duration or the intake valve timing (see Figure 12). The increase in $\mathrm{x}_{\mathrm{r}}$ is a consequence of the truncation of the exhaust stroke by the early closure of the exhaust valve. The increase in $\mathrm{x}_{\mathrm{r}}$ as a function or EVC advance occurs at a rate of $\sim 0.35 \% /{ }^{\circ} \mathrm{CA}_{\mathrm{EVC}}$, advance. The higher residual gas fraction results in an offset of the high pressure pumping loop towards higher pressures. The added residual gases decrease the cylinder temperature during combustion, lowering the heat transfer losses to the cylinder walls. However, early EVC also implies early EVO, and a reduction in the effective expansion ratio. As a result, the blow-down losses increase. These two competing effects cancel out resulting in similar GIMEP values as shown in Figure 16.

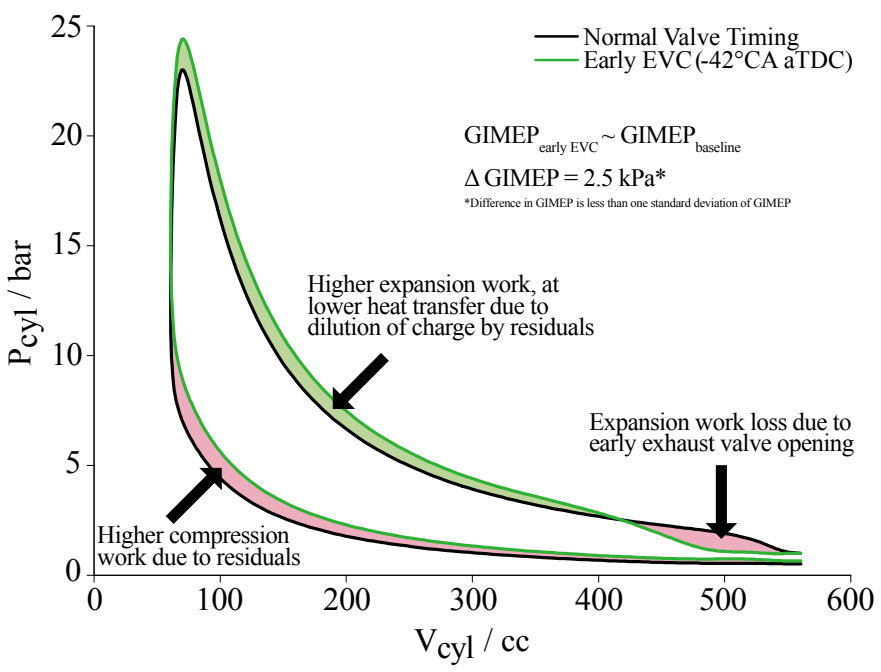

Figure 16. Comparison of the high pressure loops (linear scales) of the baseline and Early EVC valve timings (fuel mass $=14.7 \mathrm{mg} / \mathrm{cyl} . / \mathrm{cycle}$ )
The pumping loop of the Early EVC strategy also features two competing effects that limit its effectiveness for reducing the pumping losses. The additional residual gases trapped as a result of the early exhaust closure are recompressed in the late part of the exhaust stroke. As the intake valve opens, the recompression work done by the engine is lost to the intake manifold. However, the higher internal EGR requires a wider throttle opening, offsetting the losses from the recompression of the residual gases. The end result is a slight decrease in PMEP for the Early EVC strategy as shown in Figure 17.

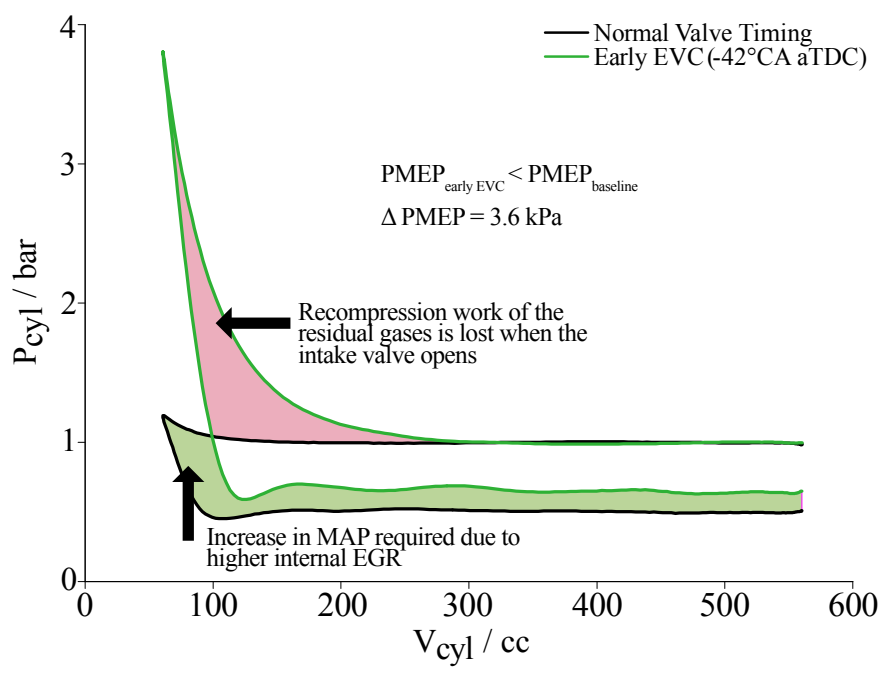

Figure 17. Comparison of the pumping loops (linear scales) of the baseline and Early EVC valve timings (fuel mass $=14.7 \mathrm{mg} / \mathrm{cyl} . / \mathrm{cycle}$ )

The Late IVO and Early EVC valve timing strategies can be combined into a single valve setting, namely Symmetric NVO, to exploit the benefits from both approaches. Figure 18 shows, in red, the pressure-volume diagram for the Symmetric NVO setting. The difference in NIMEP between the Symmetric NVO and baseline cases amounts to $29 \mathrm{kPa}$, which represents a $7.7 \%$ in net indicated thermal efficiency. Although the work performed during the highpressure loop is slightly lower in the Symmetric NVO case $\left(\right.$ GIMEP $_{\text {baseline }}-$ GIMEP $\left._{\mathrm{NVO}}=2.7 \mathrm{kPa}\right)$, the gains stemming from the pumping loop result in significant gains in NIMEP.

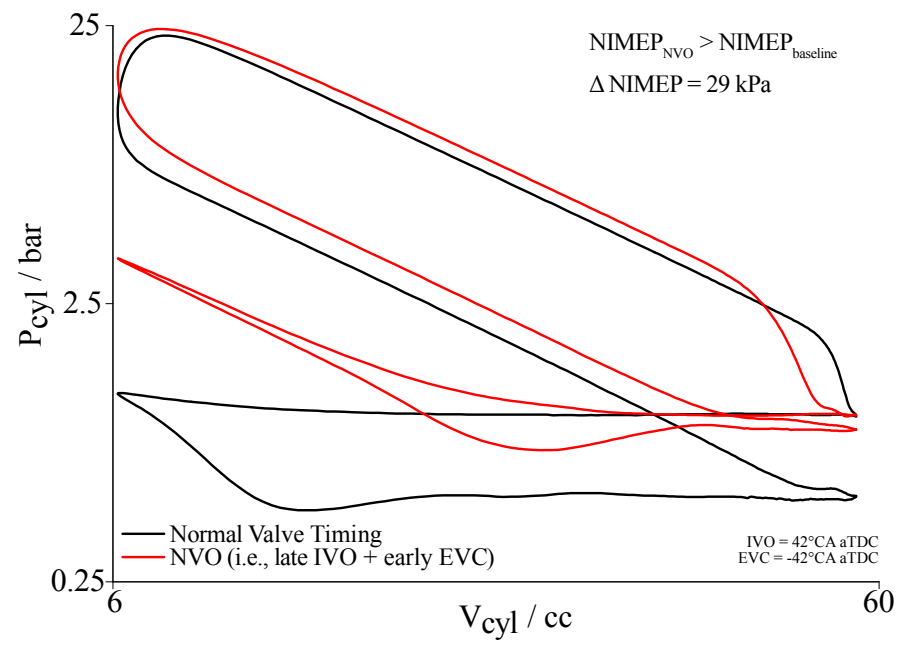

Figure 18. $\log (\mathrm{P})-\log (\mathrm{V})$ diagrams for baseline and Symmetric NVO valve timings for a constant fuel injection of $14.7 \mathrm{mg}$ per cylinder per cycle

Page 7 of 10 
The slightly lower GIMEP observed in the Symmetric NVO case is the result of the early exhaust valve timing. As was explained for the Early EVC case, the early opening of the exhaust valve in the expansion stroke results in higher blow-down losses and a lower effective expansion ratio (see Figure 16).

On the other hand, the pumping loop resulting from the Symmetric NVO setting benefits from the positive aspects of the Late IVO and Early EVC settings, while correcting the negative aspects. Figure 19 shows the pumping loops of the baseline and Symmetric NVO valve settings. The advance in exhaust valve closing results in a higher residual gas fraction, and in the recompression of these burned gases. Contrary to the Early EVC case, the intake valve remains closed during this recompression and re-expansion period, recovering the work spent in the recompression of the residual gases. As shown in Figure 19, the compression and expansion traces do not follow the exact same path, and some work is lost through heat transfer to the cylinder walls. Since the NVO is symmetric, the residual gases expand to a pressure that is slightly lower (due to the heat transfer losses) than the one present in the manifold during the exhaust process. As the intake valve opens, the pressure differential between the cylinder contents and the intake manifold are close to mechanical equilibrium. This eliminates the losses present in the Late IVO case related to the over-expansion of the residual gases (see Figure 14).

The combined effect of the higher residual gas fraction due to early exhaust closing, of the recovery of the recompression work due to the late intake opening, and of the lower effective compression ratio due to the late intake valve closure, is a significant reduction in the pumping losses. The PMEP is 0.49 bar in the baseline case, and 0.17 bar in the Symmetric NVO case; a reduction of $65 \%$.

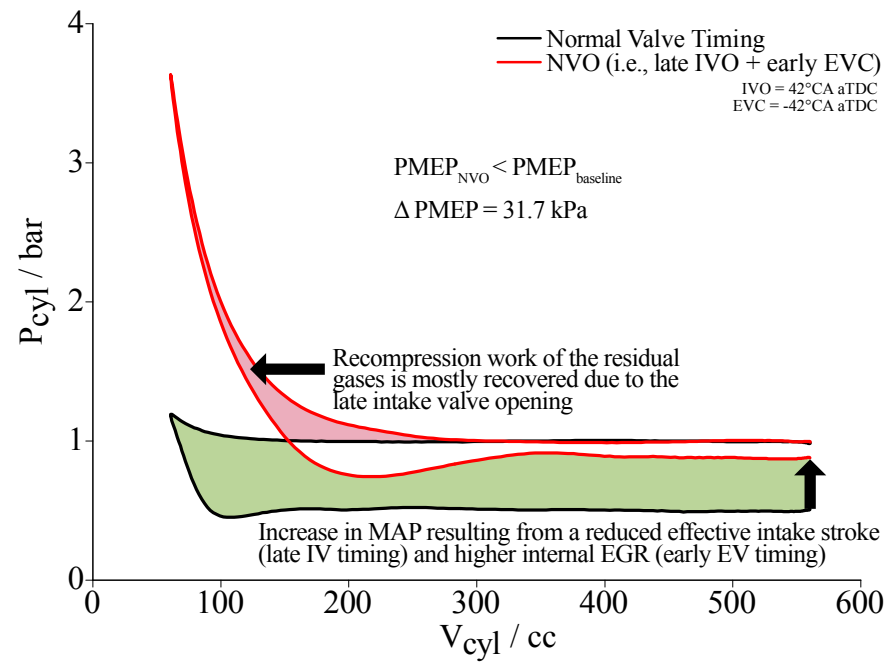

Figure 19. Comparison of the pumping loops (linear scales) of the baseline and Symmetric NVO valve timings (fuel mass $=14.7 \mathrm{mg} / \mathrm{cyl} . / \mathrm{cycle}$ )

\section{Experimental results, 16.9 and $20.1 \mathrm{mg}$ of fuel}

The different mechanisms by which the valve timing cases consider affect the net indicated efficiency, and that were described in detail in the preceding section, are the same across the different fuel flow rates studied. Nevertheless, the relative contribution of the different competing mechanisms is dependent on engine load, particularly for valve settings in the NVO range. As discussed at the beginning of the Results and discussion section (see Figure 7), the benefits of valve setting in the NVO range are reduced as the engine load increases. As previously discussed, the efficiency gains in the NVO range are traceable back to the balance between lower GIMEP and lower PMEP, with the later offsetting the reduction in work output of the high-pressure loop.

Figure 20 shows the relative change in GIMEP and PMEP for the different fuel flow rates and the different valve timing strategies. The higher engine loads resulting from the mid, and high fueling cases $(16.9 \mathrm{mg} / \mathrm{cyl} . / \mathrm{cycle}$ and $20.1 \mathrm{mg} / \mathrm{cyl} . /$ cycle) the Symmetric PVO valve timing results in significant gains in GIMEP due to the delayed exhaust opening and the resulting additional expansion work. For the Symmetric NVO strategy, the reduction in GIMEP is mainly a consequence of the early exhaust valve opening, which reduces the effective compression ratio and increases the blow-down losses. As the engine load increases, the blow-down losses also increase, relative to the baseline case. The observed gains in PMEP are consistent across the different fueling levels, ranging from under $10 \%$ for the Early EVC case, up to over $60 \%$ for the Symmetric NVO. The Symmetric NVO valve timing could not be studied for the highest fueling case because the engine reached the wide-open throttle limit before a stoichiometric mixture could be achieved.

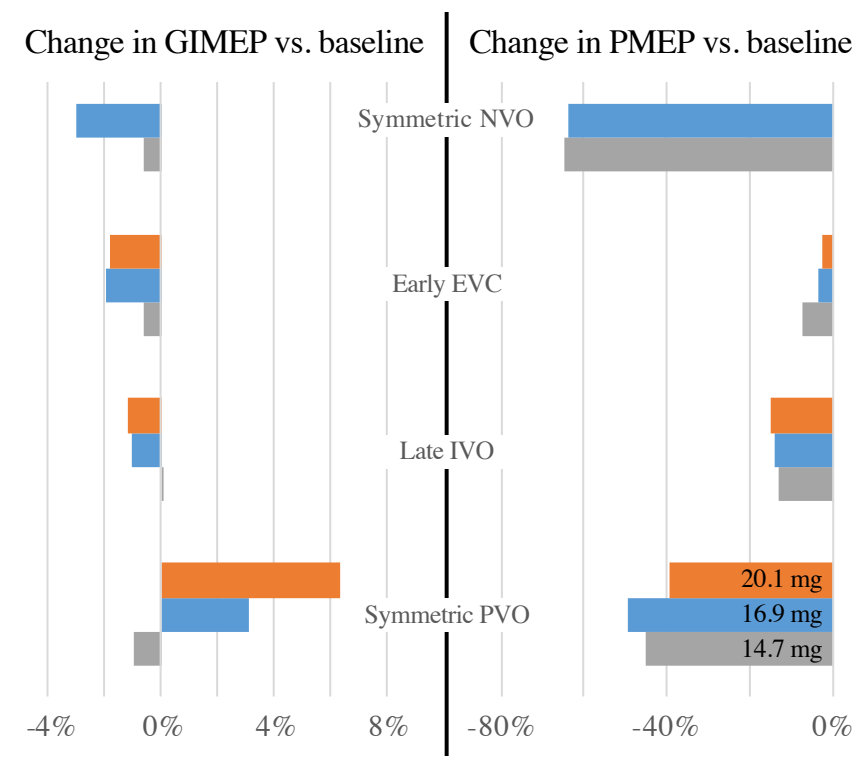

Figure 20. Change in GIMEP and PMEP with respect to the baseline for the Symmetric NVO, Early EVC, Late IVO, and Symmetric PVO.

Table 4 lists the CoV of NIMEP for the different valve timings and fueling cases. Even though the Symmetric PVO strategy invariably results in the worst combustion stability for all fueling levels, the difference in CoV between the baseline and Symmetric PVO cases reduces rapidly with increasing engine load.

Table 4. CoV of NIMEP for the three fueling cases and different valve timings

\begin{tabular}{|c|c|c|c|}
\hline & $\begin{array}{c}\text { CoV } \\
\mathbf{1 4 . 7} \mathbf{m g}\end{array}$ & $\begin{array}{c}\text { CoV } \\
\mathbf{1 6 . 9} \mathbf{~ m g}\end{array}$ & $\begin{array}{c}\text { CoV } \\
\mathbf{2 0 . 1} \mathbf{~ m g}\end{array}$ \\
\hline Baseline & $1.23 \%$ & $0.89 \%$ & $0.81 \%$ \\
\hline Late IVO & $2.04 \%$ & $1.17 \%$ & $1.03 \%$ \\
\hline Early EVC & $1.27 \%$ & $0.88 \%$ & $0.91 \%$ \\
\hline Symmetric NVO & $1.86 \%$ & $1.2 \%$ & NA \\
\hline Symmetric PVO & $19.41 \%$ & $2.1 \%$ & $1.25 \%$ \\
\hline
\end{tabular}




\section{Exhaust valve opening losses at $\mathrm{NVO}$ valve timings}

As shown in Figure 20, the benefits of symmetric NVO valve setting in reducing the pumping losses are partly offset by a reduction in the work output of the high-pressure loop, due to the early opening of the exhaust valve (see Figure 16). To understand the effect of the early EVO on the efficiency change, different exhaust valve durations were simulated at the low load point using a calibrated GT-Power model of the engine used in the experiments. A reduced exhaust duration enables the use of the advantages of Symmetric NVO (i.e., lower PMEP at low residual fraction) without the penalty of higher blowdown losses from early EVO. For the simulations, the exhaust duration was modified in $10^{\circ} \mathrm{CA}$ step from the stock $220^{\circ} \mathrm{CA}$, to a minimum of $150^{\circ} \mathrm{CA}$. The exhaust valve lift was kept at $10.3 \mathrm{~mm}$ for all exhaust durations. The IVO and EVC timings were kept constant at $42^{\circ} \mathrm{CA}$ aTDC-i and $-42^{\circ} \mathrm{CA}$ aTDC-i respectively, that is, the Symmetric NVO setting. Figure 21 shows the simulated pressurevolume traces, and the reduction in blow-by losses with shorter exhuast duration due to the later EVO at fixed EVC.

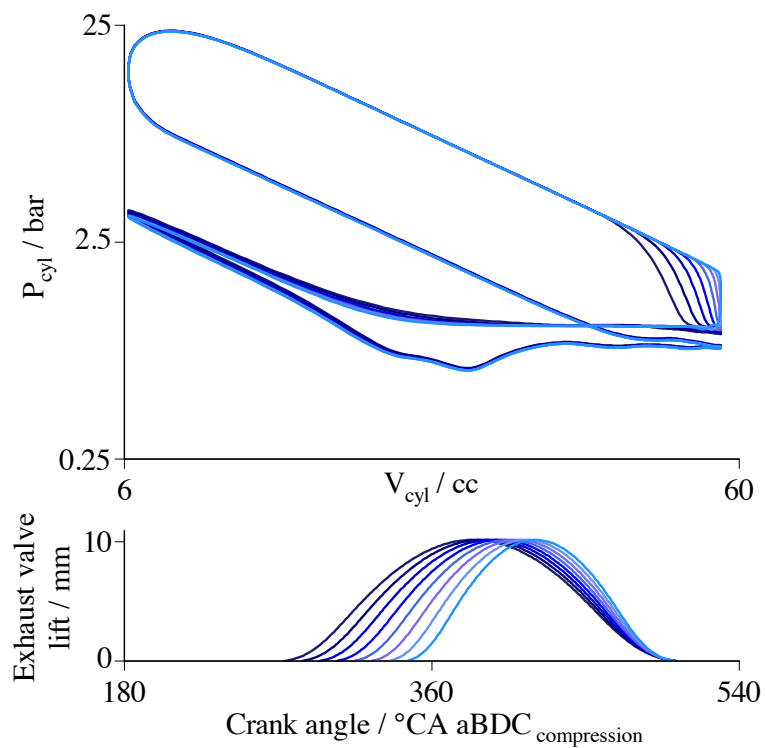

Figure 21. Simulated pressure-volume traces and exhaust valve lift profile for different exhaust opening durations using the Symmetric NVO strategy

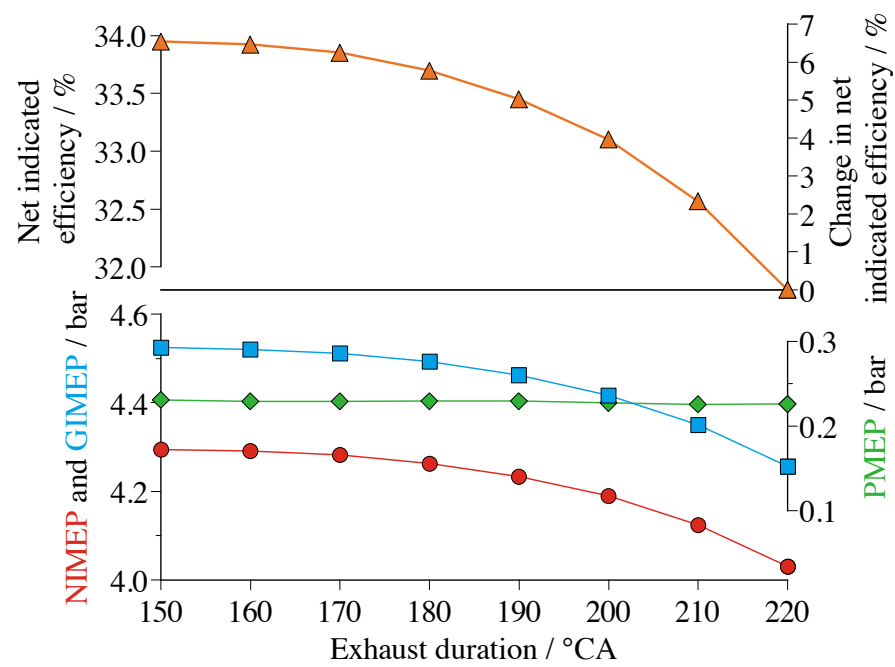

Figure 22. Effect of exhaust opening duration on net indicated efficiency and the mean effective pressures for the Symmetric NVO strategy

Page 9 of 10
As presented in Figure 22, the GT Power simulations show a 5\% increase in the indicated efficiency with a reduction of the exhaust valve duration from $220^{\circ} \mathrm{CA}$ to $190^{\circ} \mathrm{CA}$; effectively bringing the EVO event to the baseline conditions. The combined strategy of symmetric NVO with shorter exhaust duration has a potential of over $10 \%$ reduction in part-load fuel consumption.

\section{Conclusions}

The potential of negative valve overlap strategies for improving the part-load efficiency of spark ignition engines was evaluated experimentally and through simulations. The analysis was conducted at constant fuel flow rate, and included three different engine operation points. For each operating point, the influence of valve timing in the positive and negative valve overlap ranges was analyzed in detail. The following conclusions are drawn:

1. A symmetric negative valve timing strategy, consisting of late intake valve opening and early exhaust valve closing, showed significant potential for reducing the pumping losses and increasing the fuel conversion efficiency at part load. Such a valve timing strategy, with approximately $80^{\circ} \mathrm{CA}$ of negative valve overlap, results in a reduction of around $60 \%$ in pumping losses at $19 \%$ residual gas fraction.

2. The benefits of lower pumping losses from a symmetric negative valve overlap strategy are significantly impacted by the reduction in work output resulting from early exhaust valve opening. If the negative valve operation is combined with exhaust duration control, effectively delaying the exhaust valve opening, while maintain the exhaust closing timing, has a potential of over $10 \%$ reduction in part-load fuel consumption.

3. Late intake valve timing has the potential for reducing pumping losses by lowering the effective intake stroke. The latter is a result of the late intake valve closing allowing the fresh cylinder contents to be pushed back into the intake manifold, effectively reducing the amount of the trapped charge.

4. Early exhaust valve timing has a limited effectiveness in reducing the pumping losses. The higher cylinder volume at exhaust valve closing results in a recompression of a larger amount of trapped residual gases. As the intake valve opens, the compression work done by the engine is lost to the intake manifold. Nevertheless, the charge dilution by a higher residual gas fraction increases the intake manifold pressure compensating the aforementioned effect.

5. A symmetric negative overlap strategy has the potential of exploiting the advantages of late intake and early exhaust timings in pumping losses reduction, while correcting for their negative effects.

6. Traditional PVO valve timing strategies improve the part-load efficiency of the engine at part-load by reducing the pumping losses through the charge dilution caused by high rates of internal EGR. However, the applicability of PVO in the lowload range is limited by the tolerance of the combustion stability to high residual gas fractions at low loads. A symmetric PVO setting with approximately $80^{\circ} \mathrm{CA}$ of valve overlap results in a reduction of around $40 \%$ in pumping losses and $35 \%$ residual gas fraction. 


\section{References}

[1] Y. S. Jo, "More Effective Use of Fuel Octane in a Turbocharged Gasoline Engine: Combustion, Knock, Vehicle Impacts," Ph.D., Massachusetts Institute of Technology, 2016.

[2] R. P. Fitzgerald, R. Steeper, J. Snyder, R. Hanson, and R. Hessel, "Determination of Cycle Temperatures and Residual Gas Fraction for HCCI Negative Valve Overlap Operation," SAE Int. J. Engines, vol. 3, no. 1, pp. 124-141, Apr. 2010.

[3] T. Guohong, W. Zhi, W. Jianxin, S. Shijin, and A. Xinliang, "HCCI Combustion Control by Injection Strategy with Negative Valve Overlap in a GDI Engine," in SAE Technical Paper, 2006.

[4] L. Koopmans, R. Ogink, and I. Denbratt, "Direct Gasoline Injection in the Negative Valve Overlap of a Homogeneous Charge Compression Ignition Engine," in SAE Technical Paper, 2003.

[5] L. M. Olesky, J. B. Martz, G. A. Lavoie, J. Vavra, D. N. Assanis, and A. Babajimopoulos, "The effects of spark timing, unburned gas temperature, and negative valve overlap on the rates of stoichiometric spark assisted compression ignition combustion," Appl. Energy, vol. 105, pp. 407-417, May 2013.

[6] H. Persson, M. Agrell, J.-O. Olsson, B. Johansson, and H. Ström, "The Effect of Intake Temperature on HCCI Operation Using Negative Valve Overlap," in SAE Technical Paper, 2004.

[7] T. Urushihara, K. Hiraya, A. Kakuhou, and T. Itoh, "Expansion of HCCI Operating Region by the Combination of Direct Fuel Injection, Negative Valve Overlap and Internal Fuel Reformation," in SAE Technical Paper, 2003.

[8] M. Pischinger, W. Salber, F. Van Der Staay, H. Baumgarten, and H. Kemper, "Benefits of the Electromechanical Valve Train in Vehicle Operation," in SAE Technical Paper, 2000.

[9] F. Bonatesta and P. J. Shayler, "Factors influencing the burn rate characteristics of a spark ignition engine with variable valve timing," Proc. Inst. Mech. Eng. Part J. Automob. Eng., vol. 222, no. 11, pp. 2147-2158, Nov. 2008.

[10] Y. Chang, M. Wooldridge, and S. V. Bohac, "Extending the Dilution Limit of Spark Ignition Combustion via Fuel Injection during Negative Valve Overlap," in SAE Technical Paper, 2016.

[11] J. F. Rodriguez and W. K. Cheng, "Reduction of Cold-Start Emissions through Valve Timing in a GDI Engine," SAE Int. J. Engines, vol. 9, no. 2, Apr. 2016.

[12] J. F. Rodriguez and W. K. Cheng, "Analysis of NOx Emissions during Crank-Start and Cold Fast-Idle in a GDI Engine," SAE Int. J. Engines, vol. 10, no. 2, p. 2017, Mar. 2017.

[13] R. H. Kuratle and B. Märki, "Influencing Parameters and Error Sources During Indication on Internal Combustion Engines," in SAE Technical Paper, 1992.
[14] R. S. Davis and G. J. Patterson, "Cylinder Pressure Data Quality Checks and Procedures to Maximize Data Accuracy," in SAE Technical Paper, 2006.

\section{Contact Information}

Wai Cheng,wkcheng@mit.edu

\section{Acknowledgments}

The authors would like to acknowledge the support for this research by Borg-Warner, Fiat Chrysler Automobiles, Ford Motor Company, and General Motors Company through a Consortium on Engine and Fuels Research, active since 1982, under the direction of Prof. Wai K. Cheng and Prof. John B. Heywood.

\section{Abbreviations}

\begin{tabular}{|c|c|}
\hline$\eta$ NIMEP & Net indicated thermal efficiency \\
\hline${ }^{\circ} \mathbf{C A}$ & Crank Angle degree \\
\hline aTDC-c & After Top Dead Center Compression \\
\hline aTDC-i & After Top Dead Center Intake \\
\hline BDC & Bottom Dead Center \\
\hline ВМЕP & Brake Mean Effective Pressure \\
\hline CA50 & Point for $50 \%$ of heat release \\
\hline $\mathrm{CoV}$ & Coefficient of Variation \\
\hline EVC & Exhaust Valve Closing \\
\hline EVO & Exhaust Valve Opening \\
\hline GIMEP & Gross Indicated Mean Effective Pressure \\
\hline IVC & Intake Valve Closing \\
\hline IVO & Intake Valve Opening \\
\hline MAP & Manifold Absolute Pressure \\
\hline NIMEP & Net Indicated Mean Effective Pressure \\
\hline NVO & Negative Valve Overlap \\
\hline PVO & Positive Valve Overlap \\
\hline SOI & Start of Injection \\
\hline UDDS & Urban Dynamometer Driving Schedule \\
\hline VVA & Variable Valve Actuation \\
\hline VVT & Variable Valve Timing \\
\hline TDC & Top Dead Center \\
\hline $\mathbf{x}_{\mathbf{r}}$ & Residual gas fraction \\
\hline
\end{tabular}

